J Arid Land (2014) 6(1): 69-79

doi: $10.1007 / \mathrm{s} 40333-013-0192-9$

jal.xjegi.com; www.springer.com/40333

\title{
Computational fluid dynamics evaluation of the effect of different city designs on the wind environment of a downwind natural heritage site
}

\author{
BenLi LIU*, JianJun QU, QingHe NIU, JunZhan WANG, KeCun ZHANG \\ Dunhuang Gobi \& Desert Ecological and Environmental Research Station, Cold and Arid Regions Environmental and Engineering \\ Research Institute, Chinese Academy of Sciences, Lanzhou 730000, China
}

\begin{abstract}
Disturbance in wind regime and sand erosion deposition balance may lead to burial and eventual vanishing of a site. This study conducted 3D computational fluid dynamics (CFD) simulations to evaluate the effect of a proposed city design on the wind environment of the Crescent Spring, a downwind natural heritage site located in Dunhuang, Northwestern China. Satellite terrain data from the Advanced Spaceborne Thermal Emission and Reflection Radiometer (ASTER) Digital Elevation Model (DEM) were used to construct the solid surface model. Steady-state Reynolds Averaged Navier-Stokes equations (RANS) with shear stress transport (SST) $k$ - $\omega$ turbulence model were then applied to solve the flow field problems. Land-use changes were modeled implicitly by dividing the underlying surface into different areas and by applying corresponding aerodynamic roughness lengths. Simulations were performed by using cases with different city areas and building heights. Results show that the selected model could capture the surface roughness changes and could adjust wind profile over a large area. Wind profiles varied over the greenfield to the north and over the Gobi land to the east of the spring. Therefore, different wind speed reduction effects were observed from various city construction scenarios. The current city design would lead to about $2 \mathrm{~m} / \mathrm{s}$ of wind speed reduction at the downwind city edge and about $1 \mathrm{~m} / \mathrm{s}$ of wind speed reduction at the north of the spring at 35-m height. Reducing the city height in the north greenfield area could efficiently eliminate the negative effects of wind spee. By contrast, restricting the city area worked better in the eastern Gobi area compared with other parts of the study area. Wind speed reduction in areas near the spring could be limited to $0.1 \mathrm{~m} / \mathrm{s}$ by combining these two abatement strategies. The CFD method could be applied to simulate the wind environment affected by other land-use changes over a large terrain.
\end{abstract}

Keywords: computational fluid dynamics; wind environment; wind profile; large terrain; Crescent Spring

Citation: BenLi LIU, JianJun QU, QingHe NIU, JunZhan WANG, KeCun ZHANG. 2014. Computational fluid dynamics evaluation of the effect of different city designs on the wind environment of a downwind natural heritage site. Journal of Arid Land, 6(1): 69-79. doi: 10.1007/s40333-013-0192-9

The local government is planning to build two new districts in a famous intersection in Dunhuang, China along the ancient Silk Road to address problems in city space, population expansion, and the growth of tourist industry. However, considerable attention should be paid to the safety of the Crescent Spring (a desert spring), a downwind natural heritage located at the edge of the Mingsha (or Singing Sand) Megadune
(Fig. 1). This desert spring is located in a depression between two diluvial fans supplying the spring with underground water.

For decades, the Crescent Spring has suffered from water table decline because of increasing urban and agricultural water consumption, as well as sand encroachment from intensifying tourist disturbance (Dong and Bian, 2004). The spring could be in further

*Corresponding author: BenLi LIU (E-mail: liubenli@1zb.ac.cn) Received 2012-11-24; revised 2013-02-27; accepted 2013-04-28

(C) Xinjiang Institute of Ecology and Geography, Chinese Academy of Sciences, Science Press and Springer-Verlag Berlin Heidelberg 2013 


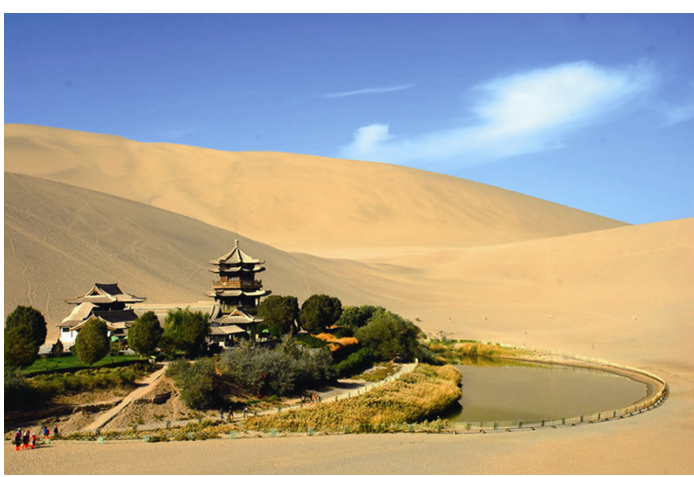

Fig. 1 Crescent Spring at Dunhuang, Gansu, China

danger if any directional wind is disturbed. Disturbance to the local multidirectional wind environment may lead to a breakdown of the sand erosion-deposition balance, cause the shifting of adjacent dunes, or result in excess sand entering the spring water. Thus, analyzing the potential influence of the proposed city design on the downwind flow environment is vital to the survival of this desert spring. Investigating the general atmospherical and meteorological characteristics of this area by using mesoscale models, such as the Weather Research and Forecasting (WRF) and the PSU/NCAR mesoscale model (MM5), is necessary. The effect of city designs on the wind distribution around the spring should also be considered because an obstacle would mostly influence the downwind wind field. Nevertheless, this study focused on the detailed distribution of wind, particularly wind with speed higher than the threshold (sand-driving) value that mainly contributes to disturbances in the wind-sand system around the spring.

Erosive winds in the earth's boundary layer are turbulent. Experimental and field studies provide insufficiently full scale data (Uchida and Ohya, 1999; Blocken et al., 2012). The Computational Fluid Dynamics (CFD) model, which has high flexibility in geometrical modeling and high near-surface meshing resolution, is the most widely used method for modeling atmospheric flow over real terrains, such as escarpments, valleys, hills, and mountains scaling from meters to a few tens of kilometer (Bitsuamlak et al., 2004). It can obtain detailed $3 D$ representation of the wind environment in the lower atmospheric boundary layer (0 to $200 \mathrm{~m}$ ) to predict the influence of an object and determine the flow field or sediment concentra- tion field of an area (Blocken et al., 2007a; Gromke et al., 2008; Kristóf et al., 2009), and to estimate the wind structure and wind resource in complex terrains such as mountains (Landberg et al., 2003; Strack and Riedel, 2004). Examples of handling areas with complex orography features include mountains in Scotland (Moreira et al., 2012) and Japan (Uchida and Ohya, 1999), the Mingsha Megadune in China (Liu et al., 2011), and large historical heritage sites in Egypt (Hussein and El-Shishiny, 2009). However, CFDbased simulation has been rarely used in studying the wind flow environment in natural heritage sites. Prediction needs can be fulfilled by adjusting the solid surface model and other surface conditions. This study aimed to model the downwind flow conditions around the Crescent Spring before and after the construction of the proposed city design using CFD simulation. Several modified designs were also simulated to investigate the impact of city size and building height reduction. Abatement suggestions to modify the design of the new city were given for the protection of the Crescent Spring.

\section{Methodology}

\subsection{Study area}

The study was conducted at Dunhuang city in Gansu province, Northwest China. Dunhuang city is located at $40^{\circ} 09^{\prime} \mathrm{N}$ and $94^{\circ} 41^{\prime} \mathrm{E}$ and has about 180,000 inhabitants. The city is an oasis surrounded by sandy and gravel Gobi deserts (Fig. 2).

The current (old) city, which is located north of the Crescent Spring, has an area of $10 \mathrm{~km}^{2}$. The proposed new city, which will be located northeast of the spring, will be constructed in two stages. The first stage will involve the construction of the administrative district (City 1). City 1, which will be located east of the old city, will have a triangular shape and a $4-\mathrm{km}^{2}$ area that covers villages, farmlands, and Gobi. The second stage will involve the construction of the business district (City 2). City 2 will have a $20-\mathrm{km}^{2}$ area that covers villages, farmlands north of the spring, Gobi land within the old city, the airport northeast of the spring, the Crescent Spring, and the world-renowned Mogao Grottoes. The height of the main buildings $(h)$ in the 


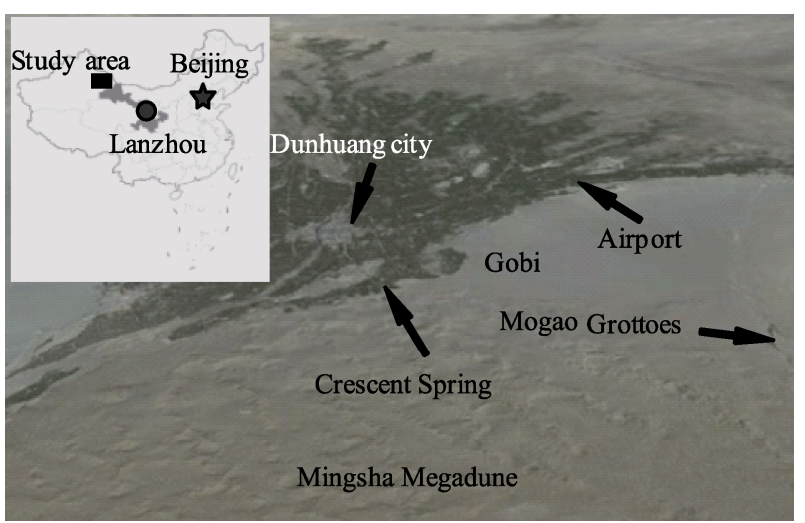

Fig. 2 Study area and location of the Crescent Spring

new city is assumed to be $18 \mathrm{~m}$, which is similar to the average height of the buildings in the old city.

Meteorological data from 2010 to 2011 show that the main local winds influencing the sand movement in the spring area are multidirectional from northeast, west, and south (Fig. 3). When investigating the influence of the proposed city on the flow field near the spring, wind crossing the city from the upwind direction should be considered. Thus, the northeast wind is chosen as the incoming airflow in this study.

\subsection{Elevation points}

Terrestrial survey or remote sensing can be used to input elevation data into the CFD model to obtain high-resolution simulations. Examples include a complex pyramid dune to the other side of the Mingsha Megadune (Liu et al., 2011) and Mount Saint Helens in the United States (Garcia, 2006). In this work, the Advanced Spaceborne Thermal Emission and Reflection Radiometer (ASTER) Digital Elevation Model (DEM) data with 30-m resolution were used to build a surface representation that is $11 \mathrm{~km}$ long (east-west direction) and $9 \mathrm{~km}$ wide (south-north direction), as shown in Fig. 4. At this spatial scale, objects at the

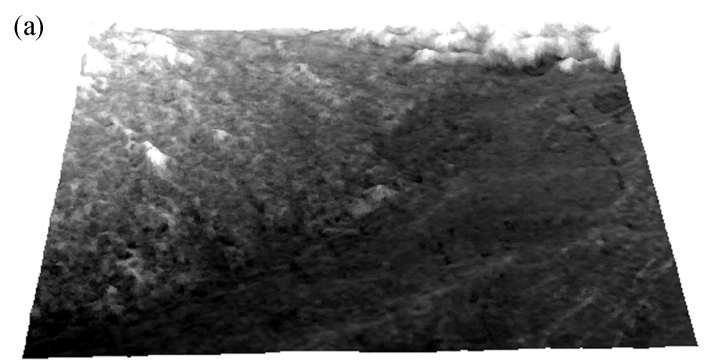

meter level can be overlooked without losing the terrain character.

Gambit software was used as model and mesh generator. Following a bottom to top approach, four adjacent points were connected to build a small face. All contiguous faces with the same land-use types were merged and then given the same surface condition. This method allowed the shapes of the dunes near the spring and the surface fluctuation to be well modeled.

\subsection{Roughness length}

CFD can be applied to obtain the roughness length of a complex surface or city given its sensitivity in this regard (Abdi and Bitsuamlak, 2010). Wind profiles will adapt to new roughness conditions over different surfaces. In the simulation model, land-use changes from Gobi or farmland to city were expressed by using different aerodynamic roughness lengths $\left(z_{0}\right)$ because of the following reasons: first, land-use mainly affects the atmospherical boundary layers as a roughness surface; second, this work aims to evaluate the

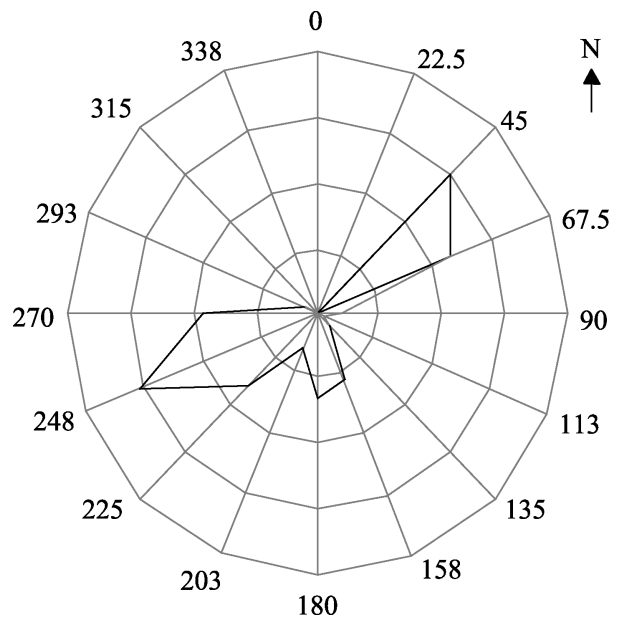

Fig. 3 Sand-driving wind rose (frequency and strength of winds from each direction) near the Crescent Spring

(b)

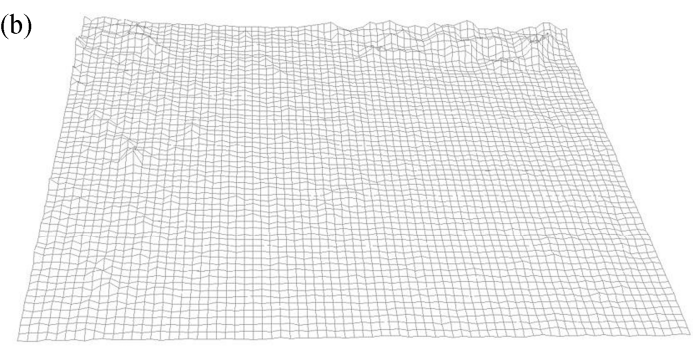

Fig. 4 Elevation map (a) and elevation points (b) of the study area. Elevation values were magnified three times to get a better view. 
downwind rather than the inside wind condition of the new city; third, the heights of the proposed buildings and trees are two orders of magnitude smaller than the city and the study area; finally, layouts of the new city are not planned, which means no design can be followed in the construction of a solid model. Therefore, only one solid model is constructed to reduce efforts in model preparation and to guarantee the consistency between different simulations for both model and mesh.

The Lettau's linear model (Lettau, 1969) is widely used in estimating $z_{0}(\mathrm{~m})$ when defining a roughness length over a solid surface. This linear model is expressed as follows:

$$
z_{0}=0.5 \mathrm{hs} / \mathrm{S} \text {. }
$$

Where $h$ is the average building height (m), s is the silhouette area $\left(\mathrm{m}^{2}\right)$, and $S$ is the spacing area $\left(\mathrm{m}^{2}\right)$. The $z_{0}$ of both new and old cities were estimated at 1.8 $\mathrm{m}$, which is equivalent to a spacing of $1.3 \mathrm{~h}$. For the greenfield with farmlands, windbreaks, and village houses, $z_{0}$ was set as $1 \mathrm{~m}$, which is within the forest roughness class summarized by Wieringa (1993) and agrees with the values provided by other works (Blocken et al., 2012). For the gravel Gobi land scattered with tombs (some of which date back to $2^{\text {nd }}$ century AD) and gravel piles (Fig. 5), $z_{0}$ was set to 0.1 and the coarse sand dune surface to 0.005 .

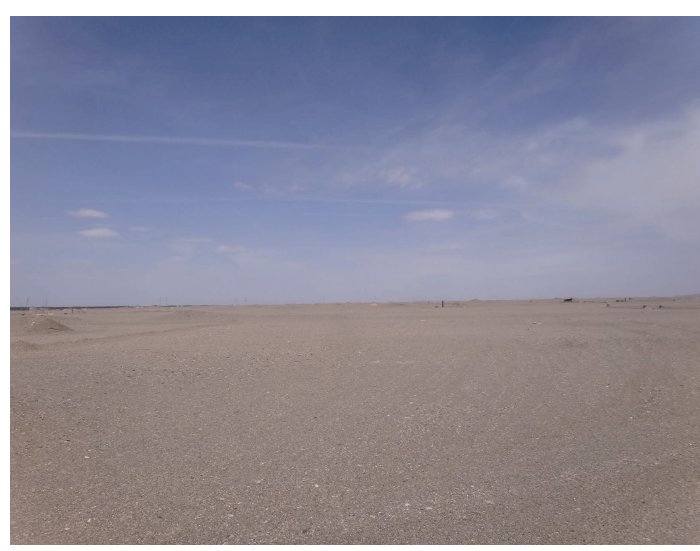

Fig. 5 Uneven Gobi with tombs and gravel piles

Here, $z_{0}$ also determines the magnitude of $K_{s}$, which is the physical roughness height in the following relation (Blocken et al., 2007b):

$$
K_{s} \approx 9.79 z_{0} / C_{s} .
$$

Where $C_{s}$ is the roughness constant of a solid surface.

\subsection{Simulation scenarios}

The simulation model named as Scenario O represents the original land-use condition, while the land-use condition of City 1 is given as F1 and that of both Cities 1 and 2 as F2. Land-use conditions and proposed changes were represented by assigning and adjusting the roughness length over corresponding surfaces.

The design of the proposed city may be modified to avoid excessive disturbance of the downwind environment near the Crescent Spring. Thus, alternative designs, such as designs with reduced city size and height, are needed. After the analysis of a group of preliminary runs, City 2 was reduced by $0.5,1,1.5,2$, and $2.6 \mathrm{~km}$ progressively from its southeastern corner to the edge of City 1, which is perpendicular to the NE winds. The five simulation cases were symbolized as R1 to R5 (Fig. 6). The roughness length of the above eight cases can be reduced and noted as $-\mathrm{L}$ to express the influence of building height on the downwind environment. Consequently, only one design with lowered height of $9 \mathrm{~m}$ (three-storey building) was considered to reduce complexity. The latter simulation indicates that City 1 does not have a significant influence on downwind flow because of the distance of City 1 to the spring and to the original existing downwind greenfield. Therefore, building height reduction was only applied to runs involving City 2.

The influence of these simulations on the downwind flow field was gauged by monitoring the wind profiles along the wind path. Wind changes vary over different underlying surfaces. Therefore, two monitoring sections that originate from the upwind airport and along trajectories toward the spring were selected. These monitoring sections correspond to the two main original surfaces outside the spring, namely, greenfield to the north and Gobi to the east-northeast (Fig. 6). The eight points of Section 1 pass through the outside of the greenfield. Particularly, these points start near the airport and then pass to the upwind, middle, and downwind edge, and 100, 300,600, and 1,000 $\mathrm{m}$ after the downwind edge of City 2. Section 2, which goes through the Gobi land, contains eleven points that are 
located nearly parallel to the points of Section 1 . The last three points of Section 2 are 1,500, 2,000, and 2,500 $\mathrm{m}$ after the downwind edge of City 2 (Fig. 6).

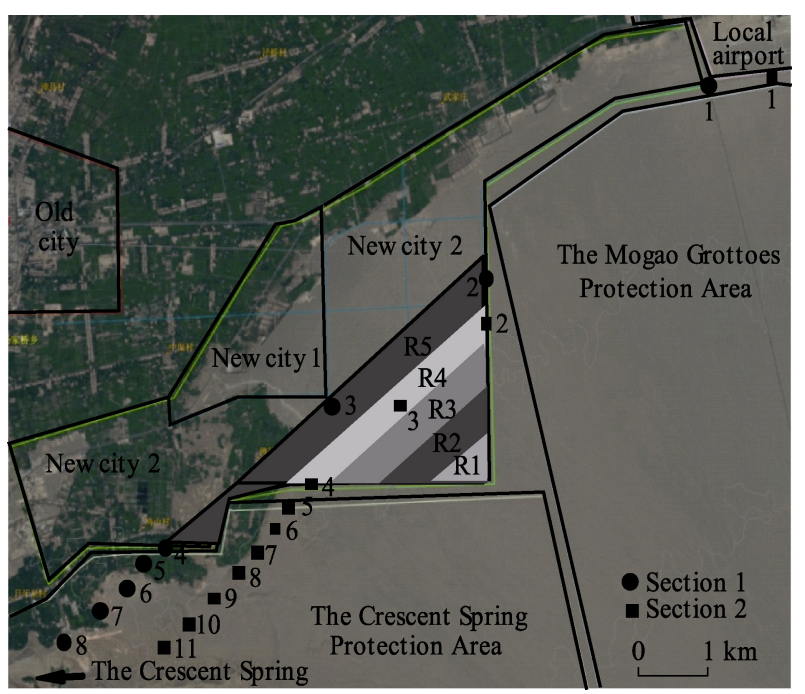

Fig. 6 Planned new districts, potential modification areas, and monitoring section transects

\subsection{CFD model}

The ANSYS FLUENT software was used to simulate airflow in the region upwind from the Crescent Spring. The simulations of turbulent air-flow for different city design scenarios were based on the steady-state Reynolds Averaged Navier-Stokes equations (RANS) and shear stress transport (SST) $k$ - $\omega$ turbulence model. The SST $k$ - $\omega$ module can capture flow details, particularly the separation and reattachment, in a computational time saving manner.

Steady RANS is the most advanced and widely used approach in modeling turbulent flow over complex surfaces (Lien and Yee, 2004; Salim et al., 2011; Moreira et al., 2012). The steady-state module was chosen because of the following reasons: 1) the information required to access the influence of a city should not be in an instant condition, and 2) an unsteady wind condition simulation over a long period would be too expensive in terms of CPU usage.

The same inlet profiles for the wind speed value at $z(\mathrm{~m})$ height, $U_{z}(\mathrm{~m} / \mathrm{s})$, turbulent kinetic energy $k$ $\left(\mathrm{m}^{2} / \mathrm{s}^{2}\right)$, and specific dissipation rate $\omega\left(\mathrm{m}^{2} / \mathrm{s}^{3}\right)$ were used in each simulation according to the following equations:

$$
U_{z}=u^{*} / \kappa \ln \left(z / z_{0}\right),
$$

$$
\begin{aligned}
k & =1.5\left(u_{\mathrm{avg}} I\right)^{2}, \\
\omega & =k^{0.5} / C_{\mu}^{0.25} / l .
\end{aligned}
$$

Where $\kappa=0.41$ is the von Karman coefficient, $u^{*}$ is the friction velocity $(\mathrm{m} / \mathrm{s}), z_{0}$ is the aerodynamic roughness length $(\mathrm{m}), u_{\text {avg }}$ is the mean flow velocity $(\mathrm{m} / \mathrm{s}), I$ is the turbulence intensity (\%), $l$ is the turbulence length scale (m), and $C_{\mu}$ is an empirical constant with a value of 0.09 . Detailed information on these equations can be found in the theory guide of ANSYS FLUENT (ANSYS, 2009).

\subsection{Model configuration}

In constructing the NE wind inlet model with flow oriented from the left of the airport to the right of the spring, the surface model was rotated $140^{\circ}$ and not $135^{\circ}$ counterclockwise because the surface is not a rigid square. The highest point $(\mathrm{H})$ in the study area is $200 \mathrm{~m}$ on the dune top at the north side of the spring. The computational domain boundaries were located $10 \mathrm{H}$ away at the upwind direction, $35 \mathrm{H}$ downwind, $25 \mathrm{H}$ at the sides and $15 \mathrm{H}$ at the top outside the area of interest. Figure 7 illustrates the extent of the computational domain.

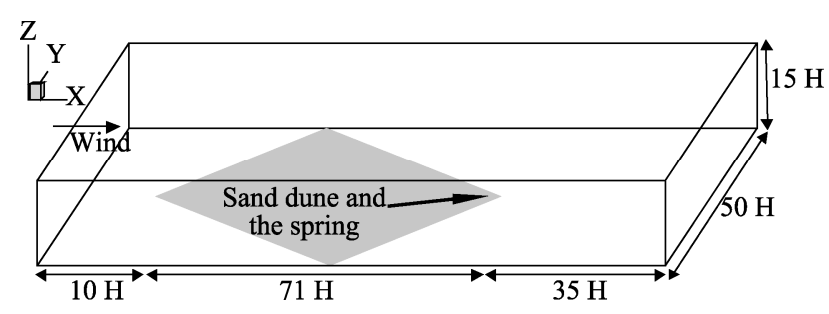

Fig. 7 Sketch of simulation model volume

The mesh generation for this highly irregular and large geometry is complicated. The model volume was divided into several sub-domains to facilitate the use of various sizes of unstructured mesh at different locations. The cells are smaller near the spring area and larger in farther areas (Fig. 8). A total of $1.6 \times 10^{6}$ grid cells were generated.

The strategy of varying the mesh sizes (large in the upstream and downstream, but small in the central region), as well as choosing the minimum upstream distance, was applied to reduce the horizontal inhomogeneity caused by the used standard wall function. The minimum mesh size was $40 \mathrm{~m}$ at the study area surface, which corresponds to the center point of the 
wall-adjacent cell at a height of $20 \mathrm{~m}$. This choice of mesh size meets the requirement imposed by the relationship between the half height of the wall-adjacent cell $Y_{p}$ and $K_{s}$ (Blocken et al., 2007b):

$$
Y_{p}>K_{s} .
$$

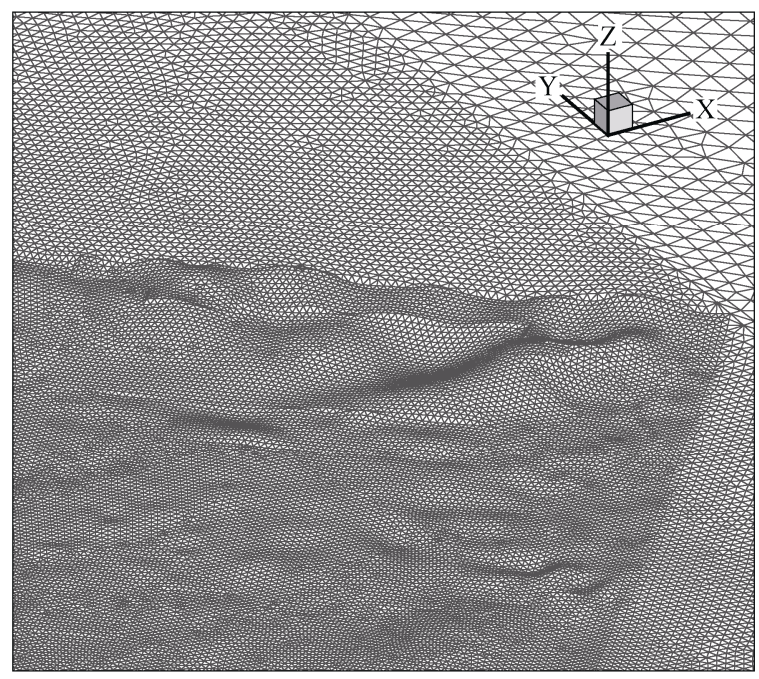

Fig. 8 Surface grids near the spring

The above relationship applies to all underlying surface conditions, except for cities that require first-layer mesh sizes of about $75 \mathrm{~m}$. The current value was still used to obtain finer results near the surface. The grid sensitivity presented in Section 1.8 agrees well with the coarser grid system.

\subsection{Other boundary conditions}

The reference wind speed for the inlet boundary, which was chosen via Eq. 3, was $10 \mathrm{~m} / \mathrm{s}$ at a $2-\mathrm{m}$ height. The reference wind is an erosive wind that could lead to sand dislocation and could affect the formation of the sand dunes around the spring. A value of 0.7 was used for $C_{s}$ of the Gobi surface to express the uneven distributed roughness elements, whereas a value of 0.5 was used for other surfaces. The downwind boundary was defined as a pressure-outlet boundary with zero pressure gradient. Symmetry boundary condition was applied on the top surface and two sides.

\subsection{Grid sensitivity analysis}

Grid sensitivity analysis was performed to obtain the grid size with refinement factor of 1.4. Two coarser girds ( $\mathrm{C} 1$ and $\mathrm{C} 2)$ were also constructed. Simulations on these grids were performed for the original land-use condition (Scenario O). Wind profiles at the airport (Point 1 in Fig. 9) and near the spring (Point 11 in Fig. 9) were for comparison. Figure 9 shows that the differences between the two coarse girds are significant, particularly at heights below $70 \mathrm{~m}$. These differences were likely caused by the low grid resolution of the $\mathrm{C} 2$ grid system near the surface. Results from the basic and the less coarse grids (C1) are close, thus indicating good computational accuracy for the basic and medium grids. However, the basic (fine) grid was selected to further analyze the flow field.

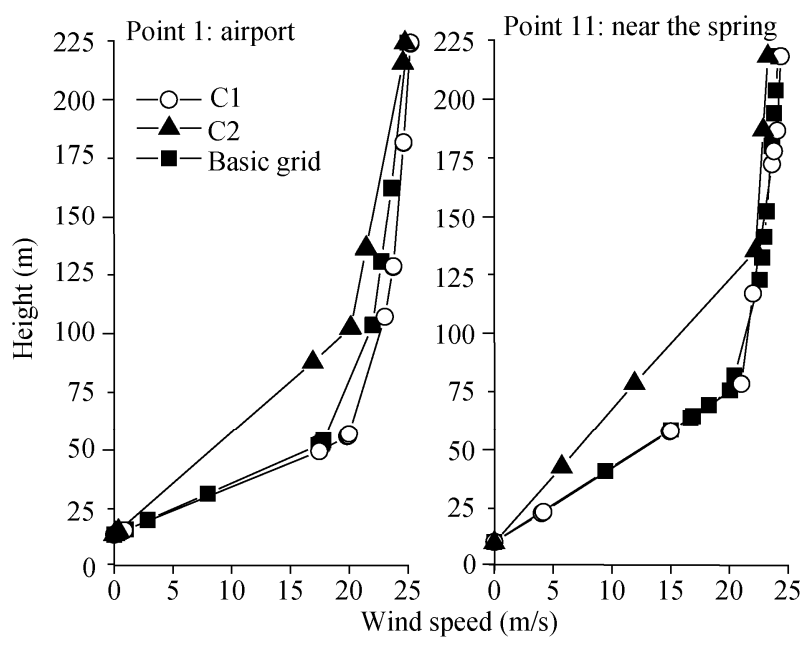

Fig. 9 Wind profile changes with different grid resolutions

\section{Results and discussion}

Fifteen scenarios including original land-use (Scenario O), two stages of city size (F1 and F2), five new city area-controlled scenarios (R1-R5), and seven city height-reduced conditions (-L for F2, F2, and R1-R5), were simulated. Simulation results show that reducing the city height has a limited abatement effect on Section 2 and has a similar outcome as that of Section 1. Thus only the results of F2L (the height of City 2 was halved) and R4L (City 2 was restricted from R1 to R4 and halved) were reported.

\subsection{Wind flow over greenfield}

The shapes of the simulated wind speed profiles vary because of changes in local elevation. Nevertheless, the simulated wind speed profiles at each point still 
follow the log law, as shown in Eq. 3. Figure 10 shows the wind profiles of Scenario $\mathrm{O}$ at eight monitoring points of Section 1. The different slopes at the lower part of each profile indicate the change and adjustment of roughness length at different surfaces.

Taking Scenario O as a reference, wind profile differences at other scenarios were mapped to show changes in wind flow (Fig. 11). The heights of these profiles were set from $0 \mathrm{~m}$ for better direct comparison at different points.

At upwind Point 1 and 2, the wind profiles under all the conditions were close to each other. Under the F1 condition (with construction of the first stage), Section 1 is out of city range, and the wind profiles at the first three points show no change, indicating the wind flow was fully developed (Lien and Yee, 2004). Although Point 4 is $4 \mathrm{~km}$ downwind from the city, it began to show a wind speed reduction of about 0.25 $\mathrm{m} / \mathrm{s}$ at $40 \mathrm{~m}$ height because of turbulent mixture effects, similar to the observation of Yassin et al. (2008). This influence decayed downwind to less than $0.1 \mathrm{~m} / \mathrm{s}$ at Point 8 near the spring.

At Point 3 which remains undisturbed under the R5 condition, all profiles except for R5 displayed significant wind speed reduction; specifically, F2 and R1-R4 showed a wind speed reduction of $2.0 \mathrm{~m} / \mathrm{s}$ at $35-\mathrm{m}$ height, whereas F2L showed a wind speed reduction of $1.0 \mathrm{~m} / \mathrm{s}$ at the same height. This result indicates that the CFD code efficiently captured the change in the underlying surface and that the wind profiles had adjusted. Similar to the F1 run, the reduction effects decayed at about $50 \%$ for all the profiles from Point 3 to 8. The wind speed of the original design of City 2 would reduce the wind speed by $1.0 \mathrm{~m} / \mathrm{s}$ at $35-\mathrm{m}$ height after the wind passes the greenfield located north of the spring. The wind speed reduction under the $\mathrm{R} 5$ condition is the same as that under the F2L condition when all areas east of the NE directional line, which is across the southeastern corner of City 1 $\left(6 \mathrm{~km}^{2}\right)$, are undisturbed. The higher the surface roughness is, the stronger wind speed reduction affects downwind distance. These observations confirm with other wind tunnel experiments (Dong et al., 2007) and numerical simulation works (Patra, 2006).

The proposed city is near the north of the spring. Therefore, lowering the height of the city would be effective in eliminating the negative influence of wind speed. Limiting the city height and restricting the city area to the R4 level could reduce the impact to $0.3 \mathrm{~m} / \mathrm{s}$ at 35-m height and less at other heights.

\subsection{Wind flow over Gobi land}

Figure 12 shows the wind profiles of Scenario $\mathrm{O}$ along Section 2, which were plotted similarly as Fig. 10. The original underlying surface along this section is Gobi without significant changes. Thus, the shapes of the wind profile resemble each other regardless of elevation.

Similar to Section 1, the wind minimally changes at Point 1 and 2 in the upwind direction of the proposed city; thus, only the wind changes at and after Point 3 are shown in Fig. 13. Section 2 is located $2 \mathrm{~km}$ from City 1 and is not as near as the center of the new city area in Section 1. Therefore, no wind speed change was noted at any point under the F1 condition. The effect of speed reduction at Point 3 was not as strong

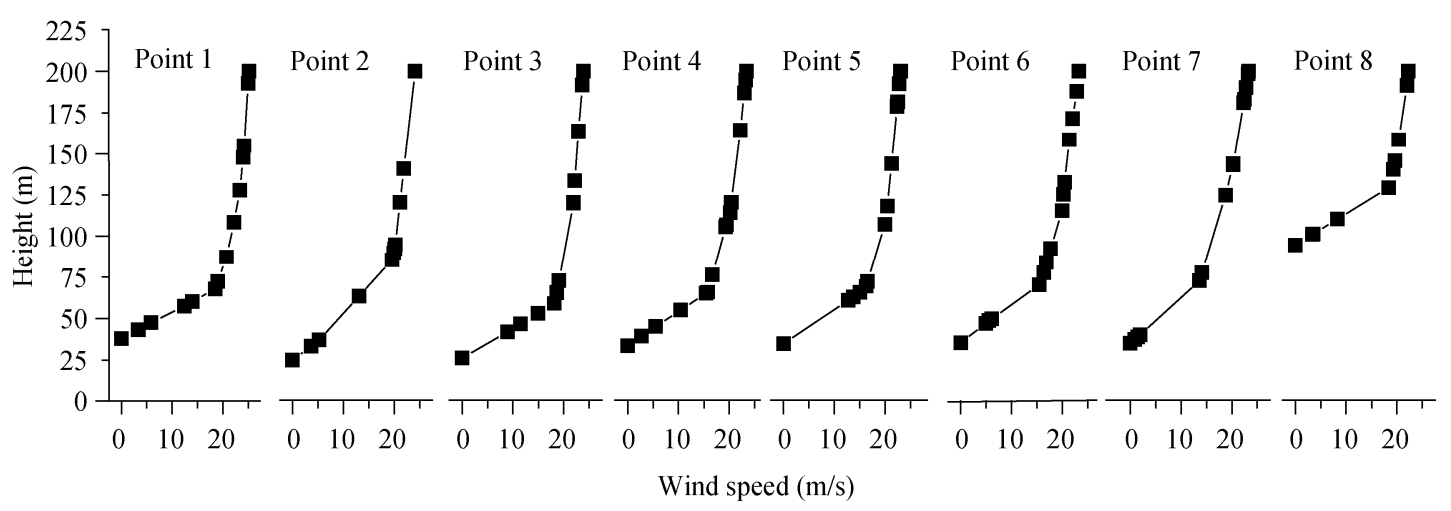

Fig. 10 Wind profiles over greenfield along Section 1 at Scenario $O$ 

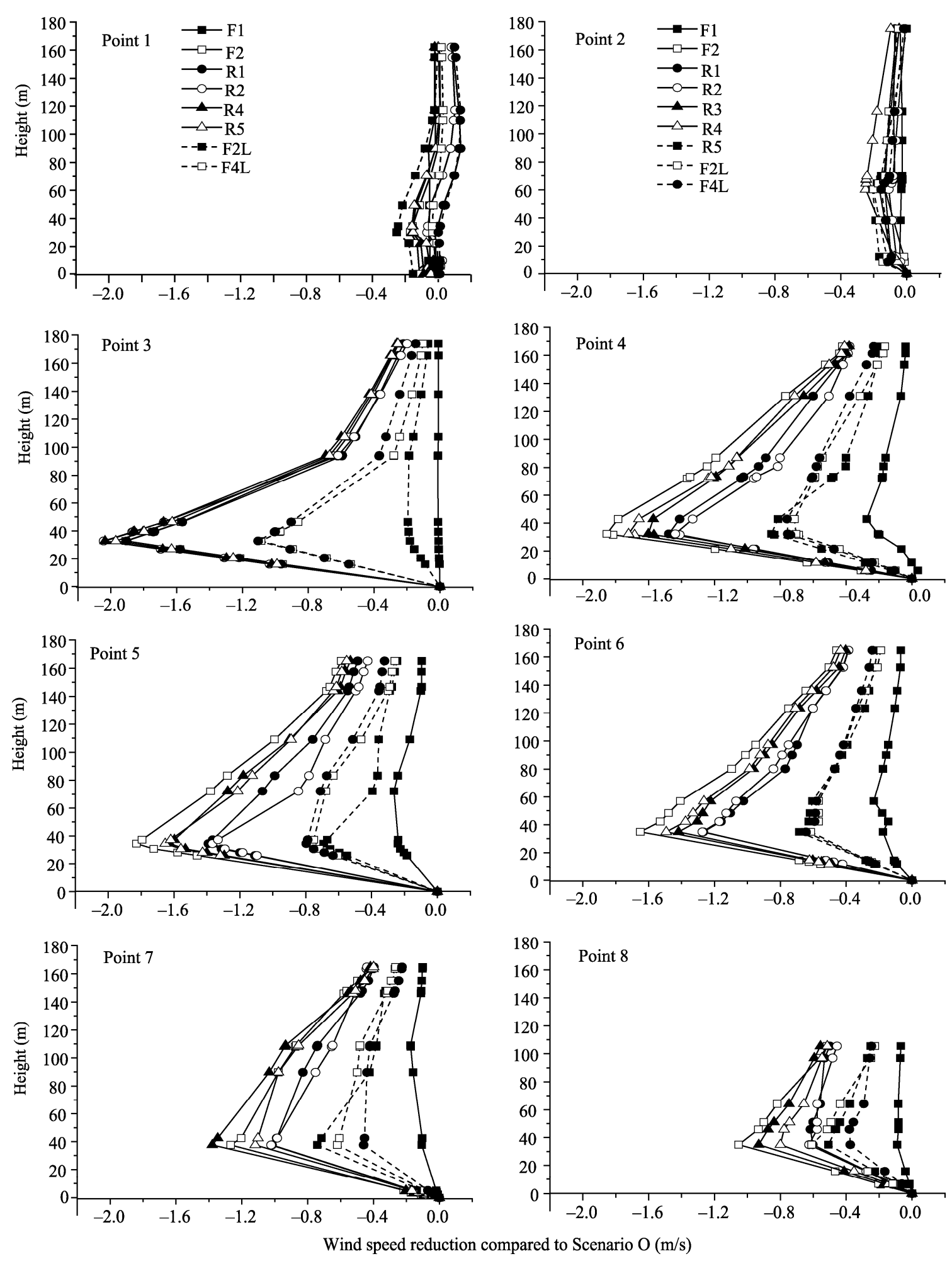

Fig. 11 Wind profile changes under different construction scenarios along monitoring Section 1

as that at Section 1. For the F2, R1, and R2 conditions at the downwind edge of City 2 (Point 4), the wind speed reduction peaked at $38-\mathrm{m}$ height with $2 \mathrm{~m} / \mathrm{s}$ and decayed to $0.9 \mathrm{~m} / \mathrm{s}$ at Point 11 .
Limiting the city area did not have a clear influence on wind speed reduction in Section 1. By contrast, R3 shares the similar ameliorative effect as F2L in Section 2 , in which the effects of wind speed reduction 


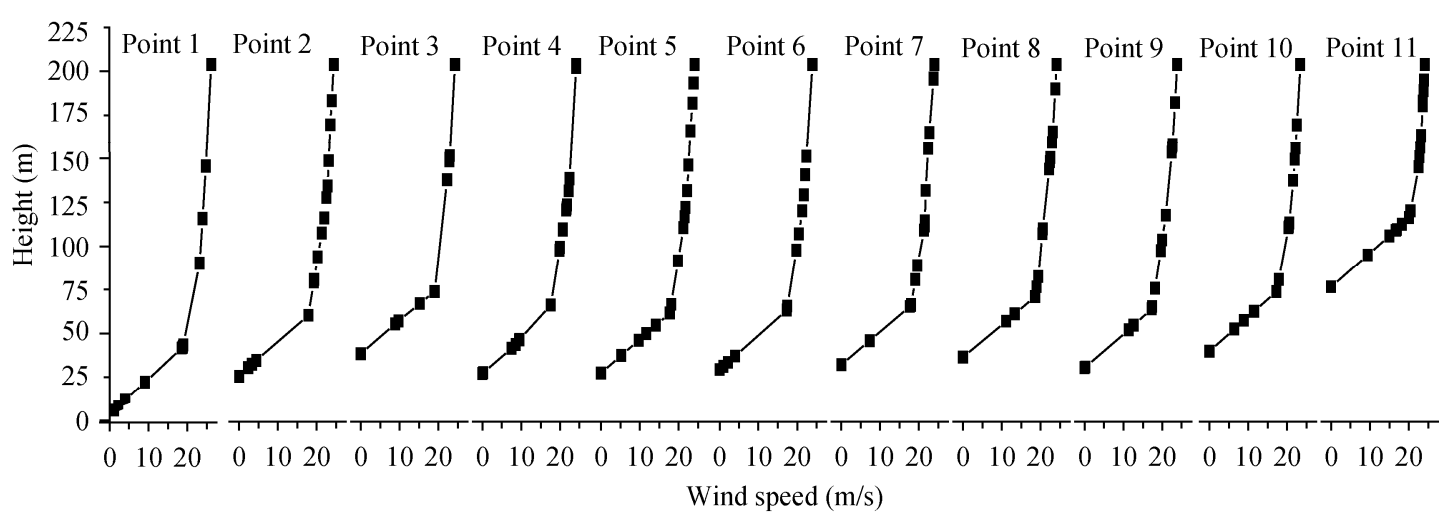

Fig. 12 Wind profiles over Gobi land along Section 2 under Scenario $O$
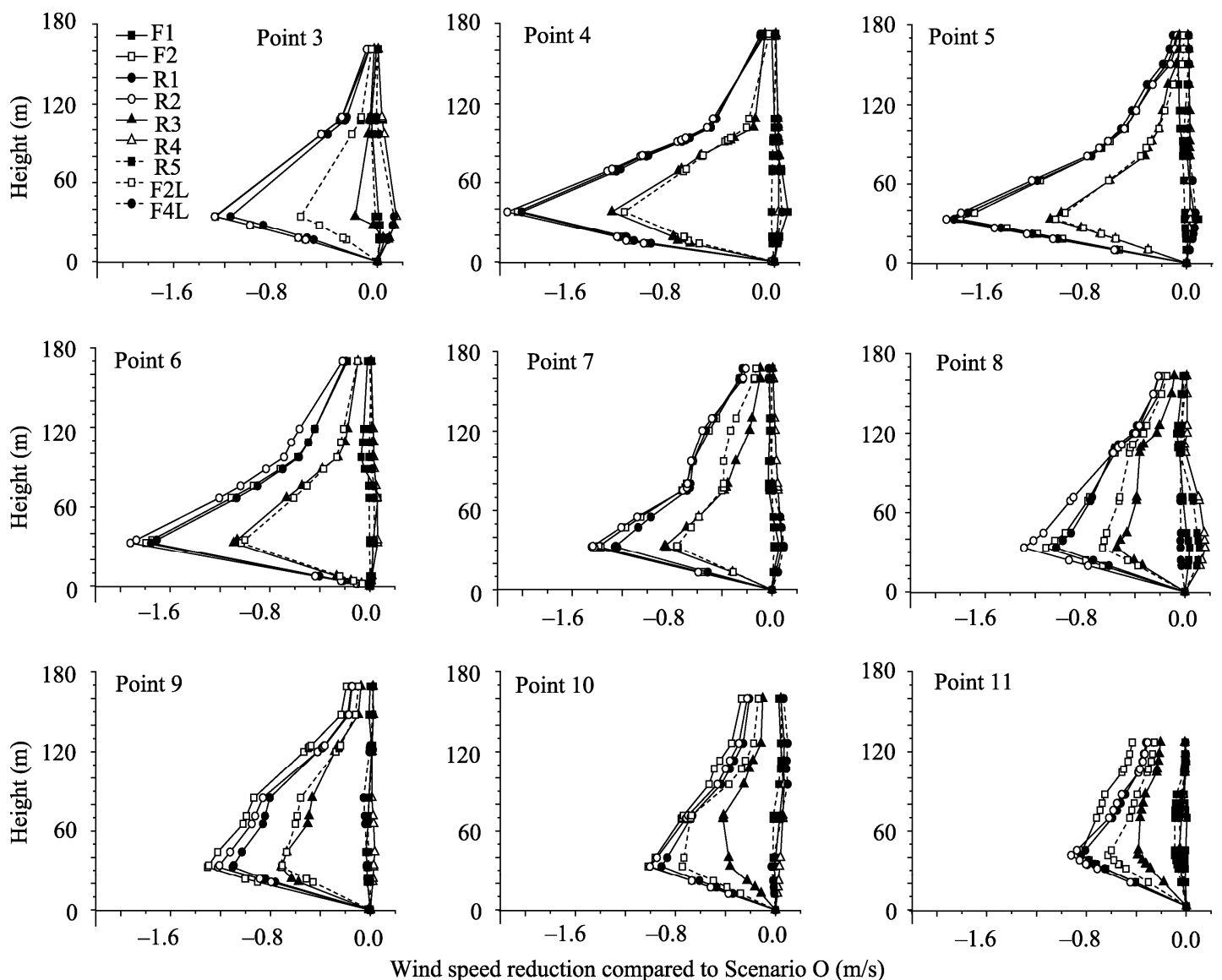

Fig. 13 Wind profile changes under different construction scenarios along Section 2

was halved. When the new city area is restricted along the upwind direction for R4 and R5 conditions, the effects of wind speed reduction was limited to less than $0.1 \mathrm{~m} / \mathrm{s}$ at Point 11 near the spring. These results indicate that limiting the upwind city area over the Gobi land is more beneficial than reducing the city height, although reducing the city height by $50 \%$ can halve the effect of wind speed reduction. Through the combining of the area and height limiting methods in $\mathrm{R} 4 \mathrm{~L}$, the reduction effect is expected to be within 0.1 $\mathrm{m} / \mathrm{s}$ at 38-m height and less at other heights.

Wind speed variation is sensitive to the proximity to roughness element (Macdonald et al., 2002). When Point 3 was about $200 \mathrm{~m}$ out of the construction area in the R4 and R4L conditions, wind speed was slightly higher than in the original condition. This increase in 
wind speed is caused by the acceleration of wind flow (turbulent mixture) around the outside edge of the city area. However, in the R5 condition, the wind changes minimally because the disturbed area was $600 \mathrm{~m}$ farther from Section 2. A similar phenomenon occurred at Point 8 , thus providing further proof that flow field variations via changing land-use changes are well simulated in the implicit model.

\subsection{Limitations}

Difficulty in synchronous field observation over large areas limits the validation of CFD simulation. For this studied issue, verifying the influence of objects on the wind environment is difficult because of the long field distance. Field measurements can also be biased because of the strong heterogeneity of the uneven and changing surface. What's worse is that the effect of changing land-use conditions cannot be achieved in real measurement. The wind tunnel experiment is a realizable method of validating the simulation; however, for this study wind tunnel experiment would experience problems regarding the scale of the possible physical model, because the city model would be only several millimeters high but meters far from the spring model. Therefore, the difference in wind flow at several meters downwind would be swamped by experimental error. Thus CFD method still works the best for the studied case as the experimental data are usually rare and not very reliable (Guilloteau and Mestayer, 2000; Moreira et al., 2012). A high precision non-contact wind field detector would make this type of wind tunnel validation possible in the future.

The huge diversity of scales between the Crescent Spring and the proposed city design requires further research of the flow field around the spring in a finer spatial resolution. A detailed analysis of climate data, meteorological simulation, wind tunnel simulation, and field measurements is needed to refine this report on the influence of proposed city designs on a downwind natural heritage site.

\section{Conclusions}

By using roughness length to implicitly express the land-use changes in a steady-state RANS CFD model, this study investigates the influence of city designs (with different sizes and heights) on wind environment approaching the Crescent Spring, a downwind natural heritage site located at the edge of the Mingsha Megadune. The CFD model is sensitive to roughness length changes and could adjust wind profiles accordingly, such as Point 3 in Section 1 (Fig. 10).

The first construction stage of the proposed city design (City 1) would have limited influence on the spring. At the $10 \mathrm{~m} / \mathrm{s}$ reference wind speed, the two-stage design of the proposed city reduces the speed of the NE wind flowing into the spring area by about $1 \mathrm{~m} / \mathrm{s}$. The second stage of the city construction (City 2) involves the greenfield near the north of the spring; thus, restricting the city height at the north of the spring is more efficient than limiting the city area when controlling the effects of wind speed reduction. The current design could lead to about a wind speed reduction of $0.9 \mathrm{~m} / \mathrm{s}$ in the wind approaching the spring to the east of the spring over the Gobi land at $38-\mathrm{m}$ height. To reduce the effect of wind speed reduction, restricting the city area to the R3 level (reduction by about $2.25 \mathrm{~km}^{2}$ ) is as efficient as halving the entire city height. By contrast, restring the city area to the R4 level $\left(4 \mathrm{~km}^{2}\right)$ would only contribute to a wind speed reduction of $0.1 \mathrm{~m} / \mathrm{s}$ for wind approaching the spring.

Reducing the size of the new city of the second stage by at least $4 \mathrm{~km}^{2}$ at the southeastern corner (R4 scenario) is suggested. The height of the city buildings should also be limited, particularly in the area north of the spring that is over the original greenfield. The NE wind that flows from Gobi land into the spring area would experience a wind speed reduction of $0.1 \mathrm{~m} / \mathrm{s}$, whereas the wind flowing north of the spring would experience a $0.3 \mathrm{~m} / \mathrm{s}$ wind speed reduction. This study shows that the wind environment in the Crescent Spring area can be maintained without modifying the original wind-sand balance, and that a balance between city expansion and natural heritage protection can be achieved.

\section{Acknowledgements}

This work was supported by the National Basic Research Program of China (2012CB026105), the National Natural Science Foundation of China (41201003, 41071009), and the China Postdoctoral Science Foundation (2012M52819). We would 
like to thank Dr. Lawrence J HAGEN and two anonymous reviewers for providing valuable suggestions on the manuscript.

\section{References}

Abdi D, Bitsuamlak G T. 2010. Estimation of Surface Roughness using CFD Simulation. The Fifth International Symposium on Computational Wind Engineering. Chapel Hill: International Association for Wind Engineering, 1-8.

ANSYS Flent Theory Guide. 2009. Shear-Stress Transport (SST) $k-\omega$ model. [2012-11-28]. https://www.sharcnet.ca/Software/Fluent12/ $\mathrm{html} / \mathrm{th} /$ node67.htm.

Bitsuamlak G T, Stathopoulos T, Bédard C, et al. 2004. Numerical evaluation of wind flow over complex terrain: review. Journal of Aerospace Engineering, 17(4): 135-145.

Blocken B, Stathopoulos T, Carmeliet J. 2007a. CFD simulation of the atmospheric boundary layer: wall function problems. Atmospheric Environment, 41: 238-252.

Blocken B, Carmeliet J, Stathopoulos T. 2007b. CFD evaluation of wind speed conditions in passages between parallel buildings - effect of wall-function roughness modifications for the atmospheric boundary layer flow. Journal of Wind Engineering and Industrial Aerodynamics, 95(9-11): 941-962.

Blocken B, Janssen W D, von Hooff T. 2012. CFD simulation for pedestrian wind comfort and wind safety in urban areas: general decision framework and case study for the Eindhoven University campus. Environmental Modelling \& Software, 30: 15-34.

Dong J, Bian Z. 2004. Proposal for the protection of natural heritage of Singing Sand Mountain and Crescent Moon Spring in Dunhuang City, China. Journal of Natural Resources, 19(5): 561-567.

Dong Z, Luo W, Qian G, et al. 2007. A wind tunnel simulation of the mean velocity fields behind upright porous fences. Agricultural and Forest Meteorology, 146(1-2): 82-93.

Garcia M J. 2006. Low altitude wind simulation over Mount Saint Helens using NASA SRTM Digital Terrain Model. Third International Symposium on 3D Data Processing, Visualization, and Transmission. NC: Chapel Hill, 535-542.

Gromke C, Buccolieri R, Sabatino S D, et al. 2008. Dispersion study in a street canyon with tree planting by means of wind tunnel and numerical investigations - evaluation of CFD data with experimental data. Atmospheric Environment, 42: 8640-8650.

Guilloteau E, Mestayer P G. 2000. Numerical simulations of the urban roughness sub-layer: a first attempt. Environmental Monitoring and Assessment, 65(1-2): 211-219.
Hussein A S, El-Shishiny H. 2009. Influences of wind flow over heritage sites: A case study of the wind environment over the Giza Plateau in Egypt. Environmental Modelling \& Software, 24: 389-410.

Kristóf G, Rácz N, Balogh M. 2009. Adaptation of pressure based CFD solvers for mesoscale atmospheric problems. Boundary-Layer Meteorology, 131(1): 85-103.

Landberg L, Myllerup L, Rathmann O, et al. 2003. Wind resource estimation - an overview. Wind Energy, 6: 262-271.

Lettau H. 1969. Note on aerodynamic roughness parameter estimation on the basis of roughness element description. Journal of Applied Meteorology, 8: 828-832.

Lien F S, Yee E. 2004. Numerical modelling of the turbulent flow developing within and over a 3-D building array, part I: a highresolution Reynolds-Averaged Navier-Stokes approach. BoundaryLayer Meteorology, 112(3): 427-466.

Liu B, Qu J, Zhang W, et al. 2011. Numerical simulation of wind flow over transverse and pyramid dunes. Journal of Wind Engineering and Industrial Aerodynamics, 99(8): 879-888.

Macdonald R W, Carter Schofield S, Slawson P R. 2002. Physical modelling of urban roughness using arrays of regular roughness elements. Water, Air and Soil Pollution: Focus, 2(5-6): 541-554.

Moreira G A, Santos A C, Nascimento C M, et al. 2012. Numerical study of the neutral atmospheric boundary layer over complex terrain. Boundary-Layer Meteorology, 143(2): 393-407.

Patra A K. 2006. Influence of wind speed profile and roughness parameters on the downwind extension of vulnerable zones during dispersion of toxic dense gases. Journal of Loss Prevention in the Process Industries, 19(5): 478-480.

Salim S M, Buccolieri R, Chan A, et al. 2011. Numerical simulation of atmospheric pollutant dispersion in an urban street canyon: comparison between RANS and LES. Journal of Wind Engineering and Industrial Aerodynamics, 99: 103-113.

Strack M, Riedel V. 2004. State of the art application of flow models for micrositing. In: Proceedings of the International Technical Wind Energy Conference. Wilhelmshaven: German Wind Energy Institute.

Uchida T, Ohya Y. 1999. Numerical simulation of atmospheric flow over complex terrain. Journal of Wind Engineering and Industrial Aerodynamics, 81: 283-293.

Wieringa J. 1993. Representative roughness parameters for homogeneous terrain. Boundary-Layer Meteorol, 63: 323-363.

Yassin M, Ohba M, Tanaka H. 2008. Experimental study on flow and gaseous diffusion behind an isolated building. Environmental Monitoring and Assessment, 147(1-3): 149-158. 